\title{
Tropism Analysis of Two Coxsackie B5 Strains Reveals Virus Growth in Human Primary Pancreatic Islets but not in Exocrine Cell Clusters In Vitro
}

\author{
M. Hodik ${ }^{*}$, A. Lukinius, O. Korsgren and G. Frisk
}

Department of Immunology, Genetics and Pathology, Rudbeck Laboratory, Uppsala University, Uppsala, Sweden

\begin{abstract}
Human Enteroviruses (HEVs) have been implicated in human pancreatic diseases such as pancreatitis and type 1 diabetes (T1D). Human studies are sparse or inconclusive and our aim was to investigate the tropism of two strains of Coxsackie B virus 5 (CBV-5) in vitro to primary human pancreatic cells. Virus replication was measured with TCID50 titrations of aliquots of the culture medium at different time points post inoculation. The presence of virus particles or virus proteins within the pancreatic cells was studied with immunohistochemistry (IHC) and electron microscopy (EM). None of the strains replicated in the human exocrine cell clusters, in contrast, both strains replicated in the endocrine islets of Langerhans. Virus particles were found exclusively in the endocrine cells, often in close association with insulin granules. In conclusion, CBV-5 can replicate in human endocrine cells but not in human exocrine cells, thus they might not be the cause of pancreatitis in humans. The association of virus with insulin granules might reflect the use of these as replication scaffolds.
\end{abstract}

Keywords: Coxsackie B virus, human enterovirus, human enterovirus capsid protein 1, human islets of langerhans, pancreas, pancreatitis, type 1 diabetes.

\section{INTRODUCTION}

Human enteroviruses (HEVs) are pathogens circulating commonly in the environment, with a seasonal peak during early fall. They belong to the Picornaviridae family, characterized by a single-stranded positive RNA genome ( 7400 nucleotides) surrounded by an icosahedral capsid around $30 \mathrm{~nm}$ in size [1]. Infection is normally asymptomatic or mild, but occasionally the virus spreads to secondary organs leading to more severe diseases such as aseptic meningitis or myocarditis [2, 3]. Coxsackie B viruses (CVBs), belonging to the HEV-B group, have been associated to pancreatic diseases such as idiopathic pancreatitis [4, 5] and type 1 diabetes (T1D) [6-12]. T1D is considered to be an immune-mediated disorder leading to selective destruction of the insulin producing beta-cells in the endocrine islets of Langerhans [13]. Very little is known about the mechanism of infection in the pancreatic exocrine cells. Studies in mice have shown that infection with several CVB strains most often leads to necrosis of the mouse exocrine cells and infiltration of immune cells, reviewed in [14]. Intriguingly the islets in these animal studies are usually left intact and uninfected, although virus proteins have been detected within endocrine cells in a few cases [15, 16]. In two separate studies of CVB-4 inoculated mice, the endocrine beta-cells appeared damaged but visible virus particles could only be detected in the exocrine cells and

*Address correspondence to this author at the Department of Immunology, Genetics and Pathology, Rudbeck Laboratory, Uppsala University, Rudbecklaboratoriet, Dag Hammarskjöldsväg 20, 75185 Uppsala, Sweden; Tel: +46735720471; Fax: +46 (18) 61102 22;

E-mail: Monika.Hodik@igp.uu.se immune-cells in the electron microscope $[17,18]$. The relevance of these studies in humans is however not clear. In human studies different serotypes of CVBs have been shown to replicate lytically in islet cells in vitro $[11,19,20]$. In children with systemic HEV infection, virus RNA [21, 22] and virus proteins [22] have been detected in the endocrine islets of Langerhans, but only occasionally in the exocrine cells [22, 23]. Moreover, a large-scale study by Richardson et al. showed that the human enterovirus capsid protein 1 (HEVP1) could be detected in the endocrine islets of about $61 \%$ of recent onset T1D subjects [10]. HEV RNA was also detected in islet cells and in a few ductal cells from T1D patients [21] and a child positive for islet related autoantibodies [9]. In none of these cases was virus detected in the exocrine cells. Only rarely has HEVs been isolated from the pancreas at onset of T1D [12].

One of the key determinants of a successful virus infection is the binding to a proper receptor. Two distinct receptors for CVBs have been characterized: The Coxsackie and Adenovirus receptor (CAR), located in tight junctions, and the decay and accelerating factor (DAF/CD55), which in some cells, is believed to act as a co-receptor, transporting the virus to the CAR [24-26]. Some strains of CVB have been shown to infect cells lacking both of these receptors, which highlights the complexity of the virus tropism [27, 28]. The reports on CAR expression on pancreatic exocrine and endocrine cells are diverging among various research groups, species and techniques [9, 16, 21, 29, 30]. Lack of DAF expression has been shown in cultured islets [21]. After entry into the host cell, the virus needs to replicate its genome and translate a number of structural and nonstructural proteins in order to produce new virions. HEV 
replication complexes are associated to the surface of virus induced vesicles/chambers [31-34]. How these vesicle membranes are formed is not clear, but markers from several organelles, e.g. from the endoplasmatic reticulum (ER) and Golgi apparatus, have been associated to them, suggesting that the virus rearrange these structures for its own propagation [32, 35-37].

Studies of the implication of HEV in T1D and pancreatitis in humans remain limited and inconclusive, partly due to limited access to primary human cells and tissues. Instead cell-lines and animal models, mostly mice, have been used to study the mechanisms behind the diseases, which might not reflect the human pathogenesis. Thus, the aim of this study was to investigate the tropism of two CVB5 strains to primary human pancreatic endocrine and exocrine cell clusters in vitro. An additional aim was to study the subcellular localization of HEV particles and the ultrastructural changes induced by infection.

\section{MATERIAL AND METHODS}

\section{Cell Cultures}

Human primary pancreatic endocrine islets were isolated in Uppsala, Sweden, according to a protocol described by Goto [38] and approved by the Local Ethics Committee. This protocol, in brief, included digestion of the pancreas using collagenase followed by density gradient separation of islets and exocrine cell clusters. Fractions of similar endocrine purity were pooled together and the percentage of islets in each pooled fraction was estimated by dithizone staining of a small sample (Fig. 1A, B). The fractions containing the least amount of endocrine cells were used for the exocrine cell cluster studies.

For virus replication studies 50 exocrine and endocrine cell clusters were handpicked carefully under a lightmicroscope (Olympus CKX41) and transferred to nonadherent 6-well culture plates (Sarstedt inc, Newton, NC, USA). Cell clusters that had been cultured up to seven days post isolation were used. For immunohistochemical studies fractions from the same donor containing approximately $80 \%$ endocrine- ("endocrine fraction") or $97 \%$ exocrine ("exocrine fraction") cell clusters were used. For ultrastructural studies a fraction containing about equal amount endocrine and exocrine cell clusters were used. Both exocrine and endocrine cells were cultured in $3 \mathrm{~mL}$ RPMI1640 medium containing $5.5 \mathrm{mM}$ glucose (SVA, Uppsala, Sweden), 2mM L-glut (Gibco-BRL, Invitrogen) and $1 \%$ Pest (SVA, Uppsala, Sweden) and $2 \%$ or $5 \%$ heatinactivated foetal bovine serum (FBS, Gibco ${ }^{\circledR}$, Invitrogen).

Primary mouse (C57BL/6J) pancreatic exocrine cell clusters were a kind gift from Quach, Uppsala University. The cell clusters, remaining after islet handpicking, were washed once in PBS and transferred to 6-well non-adherent plates (Sarstedt inc, Newton, NC, USA) and cultured in the same medium as the human pancreatic cell clusters.

Green monkey kidney (GMK) cells were cultured and maintained in T-flasks as monolayers in EMEM and 10\% FBS. For tissue culture infectious dose-50 (TCID50) titrations the cells were trypsinized (SVA, Uppsala, Sweden), transferred to 96-well plates (Corning Inc, NY, USA) and cultured in EMEM and 2\% FBS.

All cells were cultured at $37^{\circ} \mathrm{C}$ and $5 \% \mathrm{CO}_{2}$.

\section{Virus}

Two CVB-5 strains, Adr and V89-4557, and one CVB-1 strain, CVB-1-11, were used in the study. Adr was isolated from a stool sample from a boy at onset of T1D [19] and genotyped as CVB-5 (GenBank ID:FJ374273). V89-4557 was originally isolated from a patient suffering from aseptic meningitis and plaque-purified in GMK cells. Plaque able to replicate in Chinese Hamster Ovary $(\mathrm{CHO})$ cells, lacking both the CAR and the DAF receptor, was selected. Genotyping the VP1 region of this virus classified it as a CVB-5 serotype. The CVB-1-11 strain was a kind from H.Hyöty, Tampere University. It was isolated in 1983 in Argentina and obtained from the Centers for Disease Control and Prevention (CDC), Atlanta, USA. All strains were propagated in GMK cells.

\section{CVB-5 Inoculation of Primary Human and Mouse Pancreatic Cell Clusters}

For virus titer and immunohistochemistry studies, exocrine cell clusters and endocrine islets were inoculated with virus to a final concentration of $10^{2-3}$ (Adr) or $10^{2.5}$ (V89-4557) TCID50. For immunohistochemical studies with CVB-1-11 a virus concentration of CVB-1-11 $10^{3}$ TCID50 was s used. Samples of culture medium $(200 \mu \mathrm{L}$ aliquots $)$
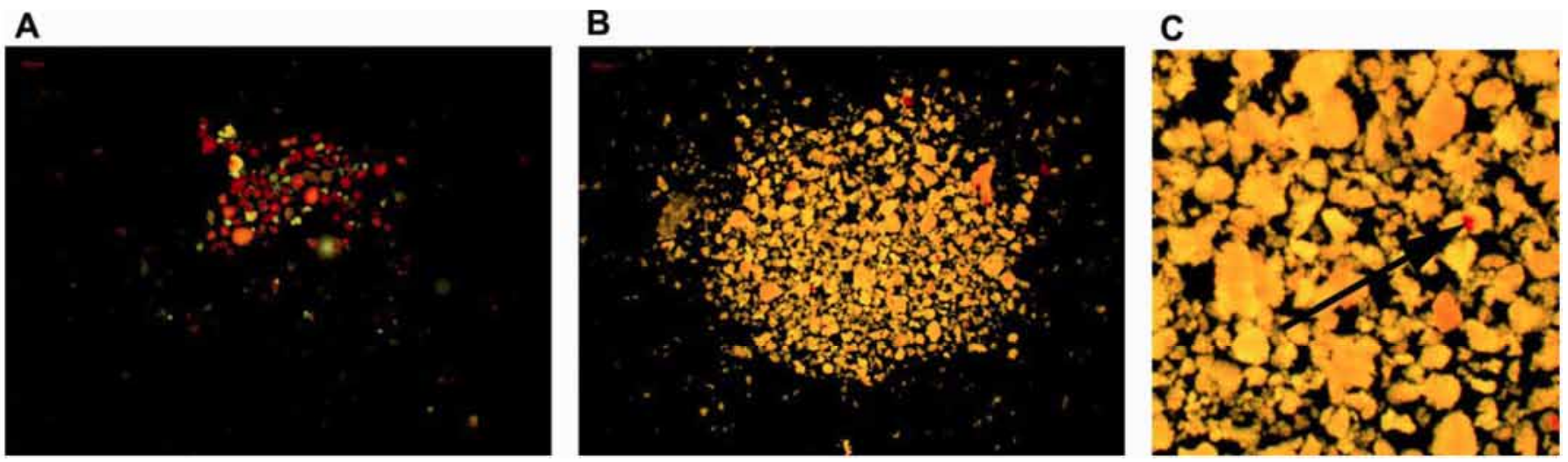

Fig. (1). Dithizone staining of two samples of human pancreatic cell clusters with varying amount of endocrine islets (stained red). The estimation of endocrine islets in the two samples is (A) $80 \%$ and (B) $2 \%$ respectively. (C) Enlarged image of the exocrine cell clusters shows an embedded endocrine islet (arrow). Figure A represents a sample from the endocrine fraction used in the immunohistochemistry study. 
were withdrawn from inoculated cell cultures on day $0,1,2-$ 3, 4-5, 6-8 post infection and stored at $-20{ }^{\circ} \mathrm{C}$ for subsequent TCID50 titrations. For ultrastructural studies, human pancreatic cells were inoculated with Adr to a final concentration of $10^{5.5}$ TCID50.

\section{Virus Replication Analysis}

Virus replication was determined by tissue culture infectious dose-50 (TCID50) titrations on Green monkey kidney cells as previously described [39]. Cytopathic effect (CPE) was monitored under a light microscope (Olympus CKX41).

\section{Cell Viability}

Cell viability of virus-inoculated and mock-infected exocrine cell clusters was determined just before virus inoculation and on the last day of the study. Cells from virus inoculated and mock-infected wells were transferred to glass tubes and washed twice in PBS. $1 \mathrm{~mL}$ pre-heated trypsin (SVA, Uppsala, Sweden) was added and the tubes were put in a $37^{\circ} \mathrm{C}$ incubator 5-10 minutes, followed by re-suspension with pipette to dissolve clusters. All cells were then transferred to a new tube with $10 \mathrm{~mL}$ RPMI 1640 supplemented with $10 \%$ FBS on ice. After a brief centrifugation most of the medium was removed. The remaining pellet was re-suspended with Trypan blue staining (Sigma-Aldrich, Stockholm, Sweden) and the viability was determined in a Bürker chamber.

\section{Immunohistochemistry}

Human virus inoculated and uninfected primary pancreatic exocrine cell clusters and endocrine islets (Fig. 1A) from the same donor were transferred to glass tubes on day four post virus inoculation. Mouse virus inoculated and uninfected primary pancreatic exocrine cell clusters were transferred to glass tubes on day two post inoculation. The clusters were washed twice in PBS and fixed in $4 \%$ formaldehyde for approximately three hours in room temperature. After dehydration in $70 \%-99.9 \% \mathrm{EtOH}$ the clusters were embedded in paraffin. Sections (5 $\mu \mathrm{m}$ thick) with at least 27 pancreatic clusters/section were cut and dried on Superfrost ${ }^{\circledR}$ plus glasslides (Thermo Scientific, Braunscweig, Germany) overnight at $37^{\circ} \mathrm{C}$, de-paraffinized and rehydrated in $99.9 \%$ $70 \% \mathrm{EtOH}$. After blockage of endogenous peroxidase for 10 minutes in room-temperature (Peroxidase blocking reagent ready-to-use) the sections were incubated with antibodies against chromogranin A (rabbit, 1:500), HEVP1 (mouse, 1:1000) or J2 anti-dsRNA (mouse, 1:1000, Scicons Hungary) or insulin (guinea-pig, 1:200) for one hour in a moist chamber. Visualization was achieved by anti-rabbit or anti-mouse Envision kit using DAB as a substrate chromogen. Samples were counterstained in hematoxylin and mounted. For chromogranin A immunolabelling of human pancreatic tissue sections $(5 \mu \mathrm{m})$, the sections were first antigen retrieved in a microwave 10 minutes at $750 \mathrm{~W}$ and then 15 minutes at $350 \mathrm{~W}$ in TE buffer ( $\mathrm{pH} 9$ ). This was followed by cooling and labeling with chromogranin A (Ready-to-use). Visualization was achieved by the Envisionkit using DAB as substrate chromogen. The Envisionkit, peroxidaseblock and antibodies (with exception of anti-dsRNA) where purchased at DAKO, Glostrup, Denmark. The slides with the HEVP1, dsRNA and chromogranin A immunolabeling were scanned on the Aperio Scanscope and the positive pixels were quantified in the Aperio
ImageScope software using the v9 algorithm. Default settings were used on all sections with the exception of the color saturation parameter which was adjusted to 0.05 .

\section{Ultrastructural Morphology}

Infected and mock-infected human primary pancreatic cells were fixed in $2 \%$ glutaraldehyde (GA) in $0.1 \mathrm{M}$ sodium cacodylate buffer supplemented with $1 \%$ sucrose, followed by $1.5 \mathrm{~h}$ post-fixation in $1 \% \mathrm{OsO}_{4}$, dehydration in $\mathrm{EtOH}$, and embedding in epoxy plastic Agar 100 (Agar Aids, Ltd, Stansted, England). Ultra-thin sections $(50 \mathrm{~nm})$ were placed on Formvar-coated $\mathrm{Cu}$-grids, contrasted with uranyl acetate and lead citrate and analyzed in a Tecnai 12 BIO Twin or Hitachi H-1700 electron microscope.

\section{Ultracytochemistry, Immunogold Technique}

Inoculated and mock-infected human primary pancreatic cells were embedded with a low temperature technique, i.e. fixed in $4 \%$ paraformaldehyde $/ 0.5 \%$ glutaraldehyde in the cacodylatebuffer for $6 \mathrm{~h}$ at $4{ }^{\circ} \mathrm{C}$, dehydrated in $50 \%-95 \%$ ethanol, followed by infiltration of the acrylic plastic Lowicryl K4M (Agar Aids Ltd, Stansted, England) and polymerization in UV-light $(360 \mathrm{~nm})$. During dehydration the temperature was lowered to $-20^{\circ} \mathrm{C}$ [40]. Ultrathin sections were placed on Formvar-coated Au-grids. Unspecific staining was blocked with $1 \%$ BSA followed by incubation with primary antibody HEVP1 (mouse; 1:1000; DAKO) and a secondary antibody conjugated with a $10 \mathrm{~nm}$ gold particle (Aurion, Netherlands). After contrasting with uranyl acetate and lead citrate the sections were analyzed in a Tecnai 12 BIO Twin or Hitachi H-1700 electron microscope.

\section{Statistical Analysis}

Comparison of cell viability between virus inoculated and mock-infected exocrine cell clusters was analyzed by pairwise Wilcoxon signed-rank test and Fisher's exact test. A P-value less than 0.05 was considered statistically significant. Data are presented as mean+SEM.

\section{RESULTS}

\section{Purity of Exocrine Cell Clusters}

The mean purity of the human exocrine cell fractions prior handpicking was estimated to $98 \% \pm 0.45 \% \quad(n=12$ donors). However, dithizone staining (Fig. 1B, C) and the more detailed chromogranin A staining (Fig. 2) reveals that it is highly likely that embedded endocrine cells will always be present, despite careful handpicking under a light microscope.

\section{CVB-5 Replication in Human Primary Pancreatic Endocrine and Exocrine Cell Clusters}

Virus titer increase was observed in the handpicked exocrine cell clusters in 3/8 (Adr) and 3/10 (V89-4557) donors respectively. The mean virus titer increase during seven days post infection in the exocrine cell clusters was Adr $0.44 \pm 0.26$ ( $n=8$ donors) and V89-4557 0.3 $\pm 0.17(n=10$ donors) $-\log$ TCID50/200 $\mu \mathrm{L}$ respectively (Fig. 3A). The virus titers in individual donors over time showed that the peak titers were reached at day three to five post infection and then declined or remained unchanged (Fig. 3B (Adr) and 3C (V89-4557)) during the remaining time-points. In the 
handpicked endocrine cell clusters virus titer increase was observed in 6/8 (Adr) and 4/5 (V89-4557) donors. The mean virus titer increase was Adr $2 \pm 0.59$ ( $\mathrm{n}=8$ donors) and V89$45572.45 \pm 0.9$ ( $\mathrm{n}=5$ donors) $-\log$ TCID50/200 $\mu$ L (Fig. 3D). In several donors the titer appeared to be still increasing after the last studied time-point (Fig. 3E (Adr) and 3F (V894557)).

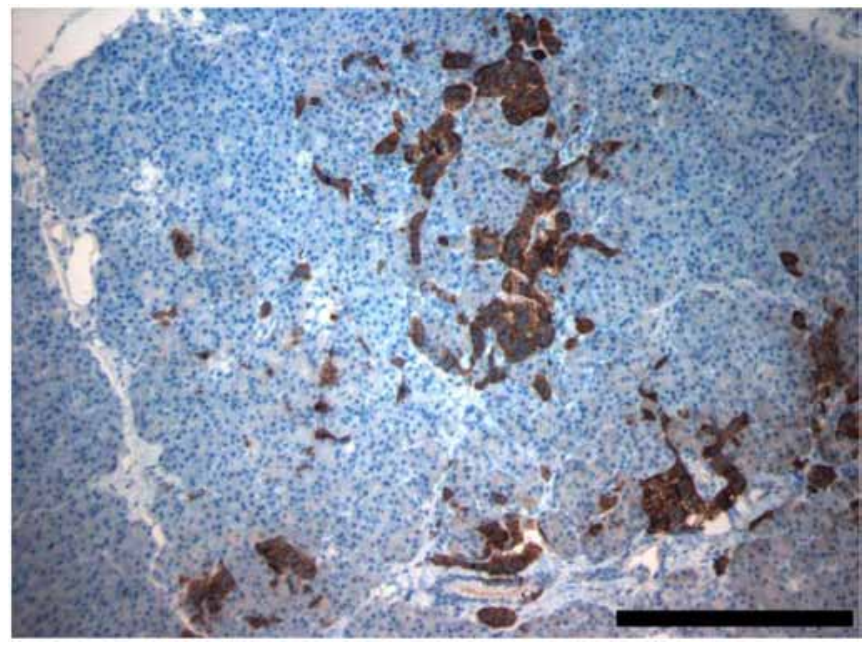

Fig. (2). Chromogranin A immunolabeling of human pancreatic tissue showing several small endocrine cell clusters scattered in the exocrine pancreas. Bar corresponds to $500 \mu \mathrm{m}$.

\section{Viability of Exocrine Cell Clusters}

The viability of exocrine cell clusters on the day of virus inoculation (d0) was $87 \% \pm 2.7 \%$ ( $\mathrm{n}=4$ donors). Day seven post virus inoculation (d7) the viability was Adr $59 \% \pm 10 \%$ ( $\mathrm{n}=6$ donors), V89-4557 57\% $\pm 7 \%$ ( $\mathrm{n}=9$ donors) and mockinfected $69 \% \pm 4 \%$ ( $\mathrm{n}=10$ donors). There was no statistical difference between the virus- inoculated and mock-infected exocrine cell clusters with neither virus strain using the Fisher's exact test however the Wilcoxon signed-rank test yielded a significant difference for V89-4557-inoculated exocrine cell clusters $(p<0.093)$. The viability of Adrinfected and mock-infected endocrine islets after 7 days in culture has in a earlier study been determined to be $61 \%$ $(\mathrm{n}=8$ donors $)$ and $83 \%(\mathrm{n}=9$ donors $)$ respectively $(\mathrm{p}<0.05)$ [19].

\section{Immunohistochemical Labeling for HEV in CVB-5 Inoculated Primary Human and Mouse Pancreatic Cell Clusters}

HEVP1 immunopositive labeling could be seen in CVB5 inoculated primary human endocrine islets (Fig. 4A, B) but not in the exocrine cell clusters (Fig. 4C-F). The labeling correlated with the endocrine marker chromogranin A (Fig. 4A, B). The fraction chromogranin A and HEVP1 positive pixels respectively in the endocrine fraction were, for Adr: $28 \%, 11 \%$ and for V89-4557: 63\%, 33\%. The corresponding values in the exocrine fraction were, for Adr: $8.7 \%, 0 \%$ and for V89-4557: 4.2\%, $0.7 \%$. The fraction dsRNA positive pixels in the exocrine fraction were, for Adr: $0 \%$ and for V89-4557: $0.2 \%$. The same staining pattern was found with the CVB-1-11 inoculated endocrine and exocrine cell clusters from the same donor as above (Supplemented Fig. 1A-C). Primary exocrine cell clusters from C57BL/6J mice $(\mathrm{n}=1)$ infected in vitro with both CVB-5 strains labeled
A Exocrine cell clusters/Mean virus titer increase
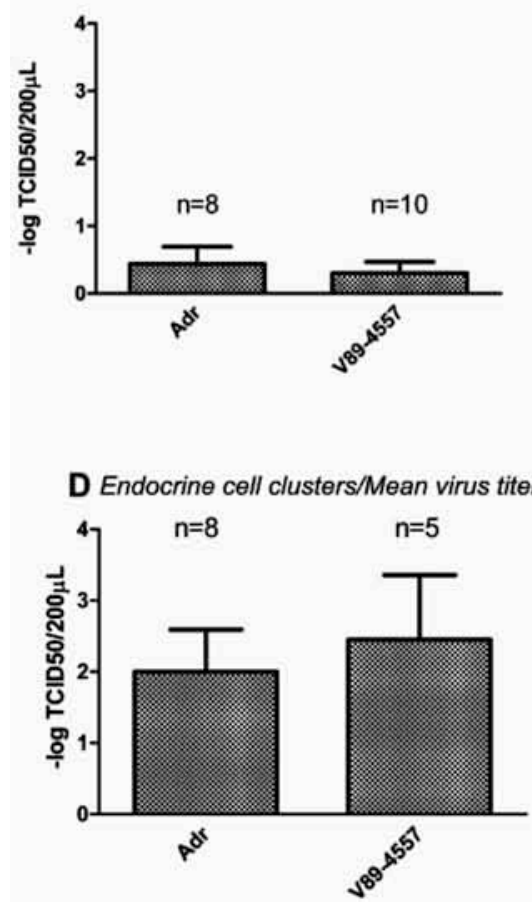

B Exocrine cell clusters/Adr+

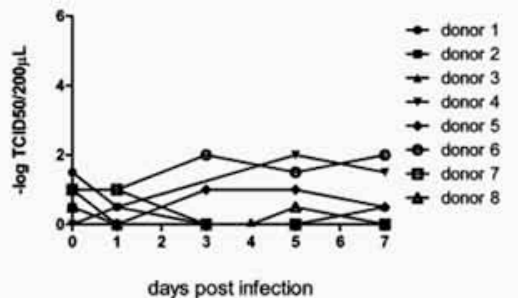

E Endocrine cell clusters/Adr+
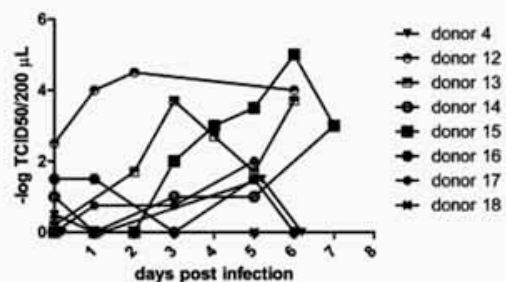

C Exocrine cell clusters $189-4557+$

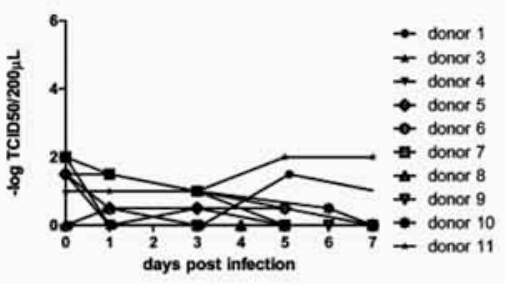

F Endocrine cell clusters $189-4557+$

Fig. (3). Mean virus titer increase in handpicked human primary (A) exocrine cell clusters inoculated with Adr and V89-4557 respectively and corresponding individual donor titers over time for (B) Adr and (C) V89-4557. Mean virus titer increase in handpicked human primary (D) endocrine cell clusters and corresponding individual donor titers over time for (E) Adr and (F) V89-4557. Virus titers are expressed as $\log \mathrm{TCID} 50 / 200 \mu \mathrm{L}$ and bars represent mean +SEM. 
A

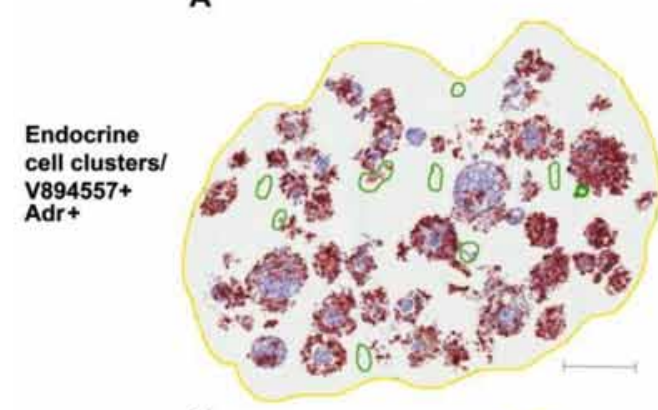

C

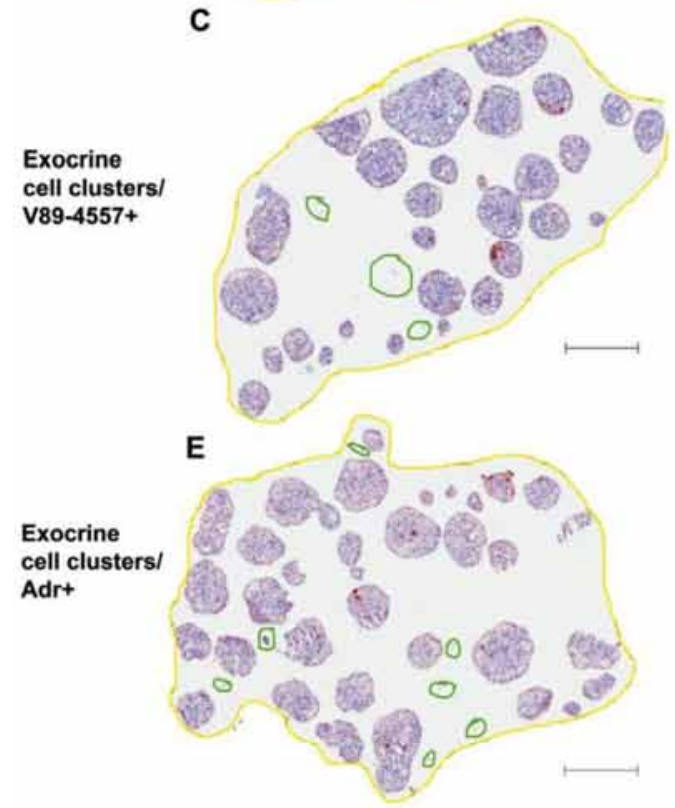

B

HEVP1

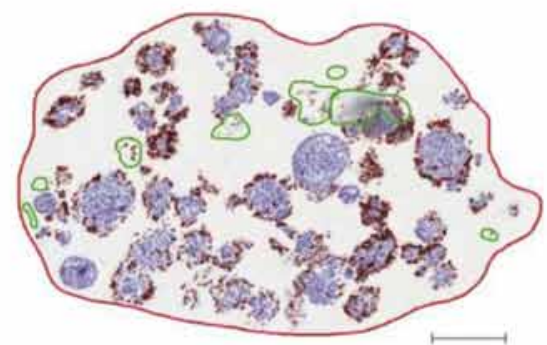

D

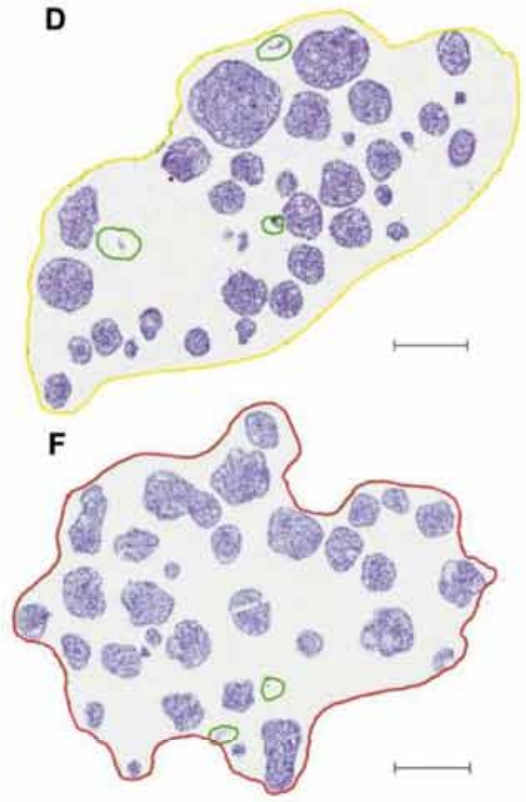

HEVP1

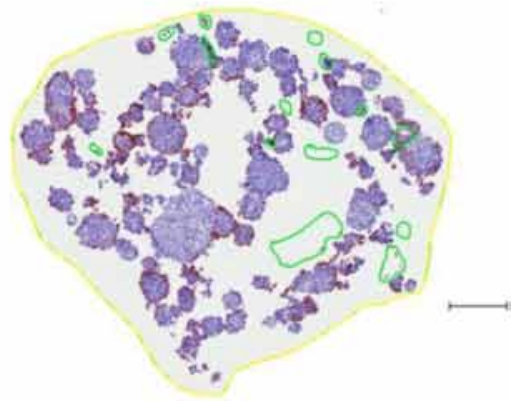

Fig. (4). Immunolabeling for virus in human primary pancreatic cell clusters on day four post virus inoculation. Sections of the human endocrine fraction inoculated with V89-4557 and Adr respectively and immunolabeled for (A) chromogranin A (V89-4557+) and (B) HEVP1 (left V89-4557+, right Adr+). Serial sections of the human pancreatic exocrine fraction from the same donor inoculated with V894557 and Adr respectively and immunolabeled for $(\mathbf{C}, \mathbf{E})$ chromogranin A and (D, F) HEVP1. Scale-bars correspond to $200 \mu \mathrm{m}$.

positive for HEVP1 and dsRNA for both virus strains and were, with the exception of few single cells, negative for insulin. The fraction HEVP1 positive pixels were, for Adr: $12 \%$ and for V89-4557: $21 \%$. The corresponding values for dsRNA were, for Adr: $34 \%$ and for V89-4557: $31 \%$.

\section{Ultrastructural Studies of Infected Primary Human Pancreatic Cells}

Virus particles (approximately $30 \mathrm{~nm}$ in size), assembled in crystal structures, could be found in several CVB-5inoculated endocrine beta-cells (Fig. 5A-G, J-L) but not in the exocrine cells (Fig. 5H) or mock-infected beta-cells (Fig. 5I). These virus crystals were immuno-positive for HEVP1 (Fig. 5K, L) and were often seen in close association to the insulin granules. Increased number of vesicular structures, vacuoles and fused/enlarged insulin granules containing several insulin crystals or barely distinguishable insulin crystals could be noted in the cytoplasm of infected cells (Fig. 5A-E). Cells with virus particles and/or virus-induced vesicles displayed nuclei $(\mathrm{N})$ with condensed chromatin (Fig. 5K). Vesicles with enclosed virus particles could sometimes be seen in the infected cells (Fig. 5G), but the majority of the virus particles were found associated with the insulin granules. HEVP1 immunolabeling showed concentration of gold particles in insulin granules, vacuoles, mitochondria and undefined structures in ultrathin sections of beta-cells with visible virus crystals, while gold particles were only occasionally seen scattered in these organelles in the mockinfected beta-cells. There was barely no HEVP1 labeling in the endoplasmatic reticulum, which could be explained by the almost complete lack of these organelles in the studied virus infected sections. Fig. (5M) shows histograms of the number of gold particles in different subcellular compartments expressed as mean+SEM. The counting of gold particles was done manually on ultrathin sections of six beta-cells with visible virus crystals and 37 mock-infected beta-cells. The number of gold particles in the virus crystals, not included in the histograms, show that the majority of the virus particles are not detected by this technique. The exocrine cell clusters, both the virus inoculated and mockinfected controls, had a generally degranulated ultrastructure. In addition, several cells were detached from each other and large autophagosomes could occasionally be seen in the cytoplasm. However, no virus particles or signs of virus infection could be seen in any of the exocrine cells. 

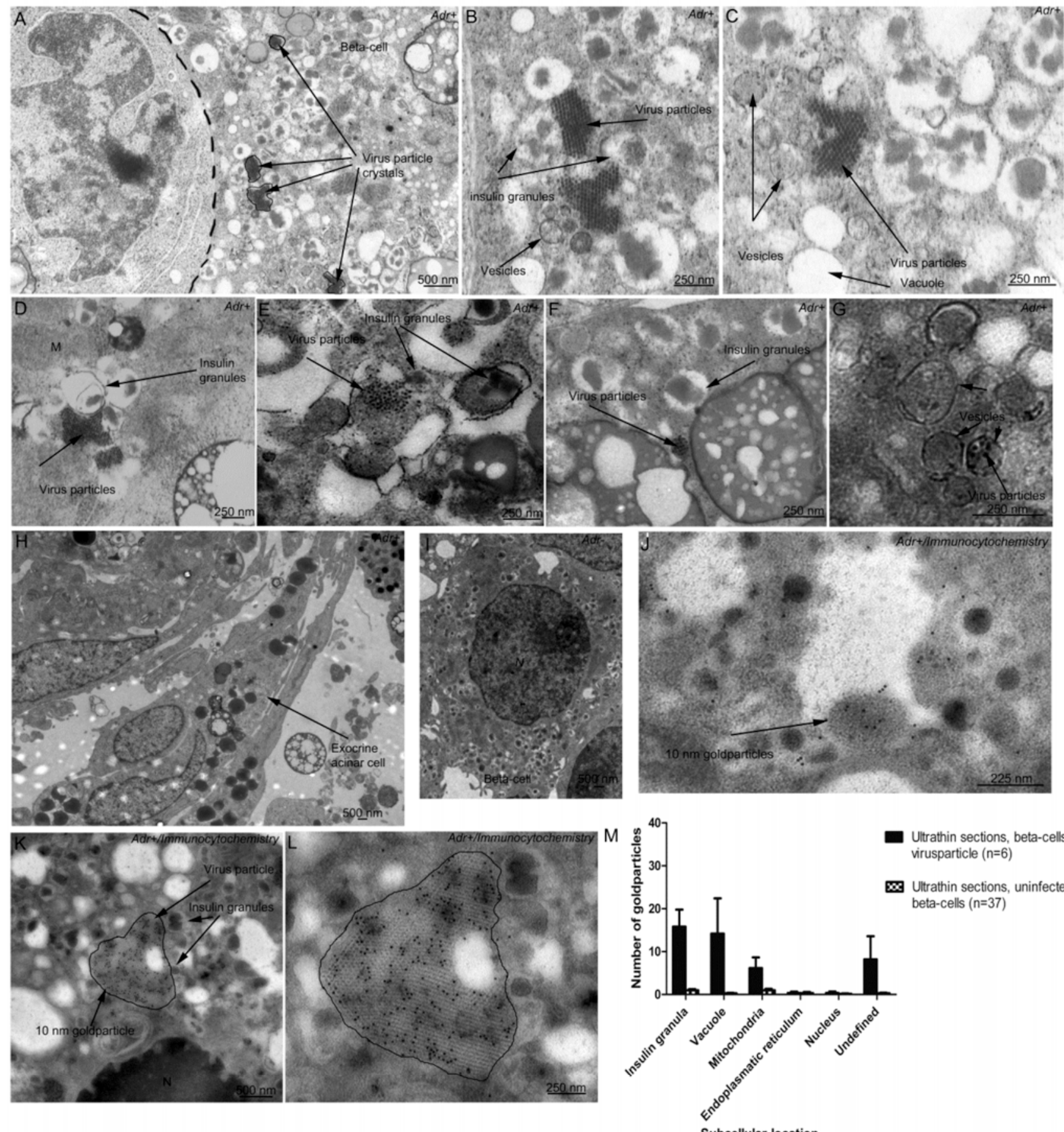

Ultrathin sections, beta-cells with virusparticle $(n=6)$

$\mathbf{0}$ Ultrathin sections, uninfected beta-cells ( $n=37$ )

Fig. (5). Ultrastructural micrographs of CVB-5-inoculated human primary pancreatic cell clusters. (A) Virus particle crystals in a beta-cell. (B-F) Detailed morphology shows association of virus particles to insulin granules and cytoplasmic membranous vesicles and vacuoles. (G) Vesicular structures enclosing virus particles $(\mathbf{H})$. No virus particles could be observed in the exocrine cells or in (I) mock-infected betacells. (J-L) Immunocytochemical images of virus-infected beta-cells. The black dots are enterovirus protein 1 (HEVP1) labeled with secondary antibodies coupled with $10 \mathrm{~nm}$ gold particles. (M) Subcellular location of HEVP1 in ultrathin sections of beta-cells with observable virus crystals $(n=6)$ and mock-infected beta-cells $(n=37)$. The bars represent the mean number of gold particles per beta-cell section+SEM, not including the gold particles in the large virus crystals. $\mathrm{N}=$ Nucleus, $\mathrm{M}=$ Mitochondria.

\section{DISCUSSION}

Immunolabeling of HEVP1, dsRNA and the electron micrographs showed that the two CVB-5 strains used in this study could not replicate in human exocrine cell clusters in vitro. This was also shown for a CVB-1 strain by immunohistochemical technique. These results diverge from what has been seen in numerous mouse studies in vivo [14, $17,29,41]$ and in vitro (present study). Our results are further supported by studies of children with systemic HEV infections, in which viral RNA was detected in the islets but not in the exocrine pancreas [21]. The minor titer increase 
seen in a few donors is likely to be due to one or several cellular subpopulations, e.g. endocrine cells endothelial cells, ductal cells or blood cells which all have shown to be susceptible for HEV infection [11, 20, 21, 42, 43]. This is further supported by the rapidly declining virus titers after the initial increase in exocrine cell clusters from organ donors. The chromogranin A and dithizone staining clearly shows that endocrine cells are present in various amounts even in handpicked exocrine cell clusters, suggesting that this is the main replication source. In addition to potentially different expression of virus receptors, variations in antiviral response between virus-inoculated cells, could contribute to the divergence in virus tropism. IFN response is an important tropism determinant which has been shown in various HEV infected tissues $[44,45]$ including human and mouse islets $[46,47]$. However, if the difference in antiviral defence can explain the tropism patterns seen between the exocrine and endocrine cells and between the species in this study remains to be studied.

Our findings show for the first time that CVB infections might not be a major cause of pancreatitis, although it cannot be excluded that there exists susceptible individuals or specific virus serotypes/strains that have tropism for the human exocrine pancreas.

The second aim in our study was to determine the subcellular location of HEV in virus-inoculated pancreatic cells. It was shown that virus particles were observed restrictively in endocrine cells, almost exclusively in betacells. The virus particles were often assembled in crystalline structures and the infected cells displayed chromatin condensation and increased number of vesicle and vacuoles, which are hallmarks of HEV infection [11]. Interestingly the virus particles were mainly found in close association to insulin granules, both the membranes and the core. The insulin granules in infected cells were often enlarged and contained more than one insulin crystal or barely recognizable insulin crystals. The close association of virus particles to insulin granules suggests that the virus can utilize these as replication scaffolds and/or affect the secretion of insulin. A normal beta-cell contains over 10.000 insulin granules (reviewed in [48]), which might enable efficient virus propagation. This is consistent with previous studies, in which it has been shown that HEV replication complexes often contain markers from the endoplasmatic reticulum and Golgi apparatus $[32,36]$ as well as proteins from the secretory pathway $[33,37]$.

In conclusion the tropism of two CVB-5 strains is in vitro restricted to human primary pancreatic endocrine cells. This is the opposite from what has been shown in mice studies in which the exocrine cell clusters are infected while the islets usually are spared.

\section{CONFLICT OF INTEREST}

The authors confirm that this article content has no conflict of interest.

\section{ACKNOWLEDGEMENTS}

We thank the islet isolation team for islet- and exocrine cell cluster preparations and Inga Hansson and Anders Ahlander for their technical assistance. The work was supported by funding from the European Union's Seventh
Framework Programme PEVNET [FP7/2007-2013] under grant agreement number 261441 and from Diabetes Research Wellness Foundation Non-Clinical Research Fellowship, Barndiabetesfonden, JDRF-nPOD-V and the Swedish diabetes association.

\section{SUPPLEMENTARY MATERIAL}

Supplementary material is available on the publisher's web site along with the published article.

\section{REFERENCES}

[1] King AMQ. Picornaviridae. In: Van Regenmortel MHV, Ed. Virus Taxonomy: Seventh report of the international Comittee for the taxonomy of viruses. New York: Academic Press 2000; pp. 657-73.

[2] Kandolf R, Sauter M, Aepinus C, Schnorr JJ, Selinka HC, Klingel $\mathrm{K}$. Mechanisms and consequences of enterovirus persistence in cardiac myocytes and cells of the immune system. Virus Res 1999; 62: $149-58$.

[3] Rotbart HA. Enteroviral infections of the central nervous system. Clin Infect Dis 1995; 20: 971-81.

[4] Ursing B. Acute pancreatitis in coxsackie B infection. Br Med J 1973; 3: 524-5.

[5] Ozsvar Z, Deak J, Pap A. Possible role of Coxsackie-B virus infection in pancreatitis. Int J Pancreatol 1992; 11: 105-8.

[6] Frisk G, Fohlman J, Kobbah M, et al. High frequency of Coxsackie-B-virus-specific IgM in children developing type I diabetes during a period of high diabetes morbidity. J Med Virol 1985; 17: 219-27.

[7] Frisk G, Friman G, Tuvemo T, Fohlman J, Diderholm H. Coxsackie B virus IgM in children at onset of type 1 (insulindependent) diabetes mellitus: evidence for IgM induction by a recent or current infection. Diabetologia 1992; 35: 249-53.

[8] Gamble DR. A possible virus etiology for juvenile diabetes. In: Kreutzfeld W, Kobberling J, Neel J, Eds. The genetics of diabetes mellitus. Berlin: Springer Verlag 1976: pp. 95-105.

[9] Oikarinen M, Tauriainen S, Honkanen T, et al. Analysis of pancreas tissue in a child positive for islet cell antibodies. Diabetologia 2008; 51: 1796-802.

[10] Richardson SJ, Willcox A, Bone AJ, Foulis AK, Morgan NG. The prevalence of enteroviral capsid protein vp1 immunostaining in pancreatic islets in human type 1 diabetes. Diabetologia 2009; 52 : 1143-51.

[11] Roivainen M, Rasilainen S, Ylipaasto P, et al. Mechanisms of Coxsackievirus-Induced Damage to Human Pancreatic \{beta\}Cells. J Clin Endocrinol Metab 2000; 85: 432-40.

[12] Yoon J-W, Austin M, Onodera T, Notkins AL. Virus-Induced Diabetes Mellitus. N Engl J Med 1979; 300: 1173-9.

[13] Gepts W. Pathologic anatomy of the pancreas in juvenile diabetes mellitus. Diabetes 1965; 14: 619-33.

[14] Ramsingh AI. Coxsackieviruses and pancreatitis. Front Biosci 1997; 2: e53-62.

[15] Bopegamage S, Kovacova J, Vargova A, et al. Coxsackie B virus infection of mice: inoculation by the oral route protects the pancreas from damage, but not from infection. J Gen Virol 2005; 86: 3271-80.

[16] Drescher KM, Kono K, Bopegamage S, Carson SD, Tracy S. Coxsackievirus B3 infection and type 1 diabetes development in NOD mice: insulitis determines susceptibility of pancreatic islets to virus infection. Virology 2004; 329: 381-94.

[17] Burch GE, Harb JM. Electron microscopic studies of viral pancreatitis in coxsackie B4 virus infected mice. Exp Mol Pathol 1979; 31: 23-35.

[18] Harrison AK, Bauer SP, Murphy FA. Viral pancreatitis: ultrastructural pathological effects of Coxsackievirus B3 infection in newborn mouse pancreas. Exp Mol Pathol 1972; 17: 206-19.

[19] Elshebani A, Olsson A, Westman J, Tuvemo T, Korsgren O, Frisk G. Effects on isolated human pancreatic islet cells after infection with strains of enterovirus isolated at clinical presentation of type 1 diabetes. Virus Res 2007; 124: 193-203.

[20] Frisk G, Diderholm H. Tissue culture of isolated human pancreatic islets infected with different strains of coxsackievirus B4: assessment of virus replication and effects on islet morphology and insulin release. Int J Exp Diabetes Res 2000; 1: 165-75. 
[21] Ylipaasto P, Klingel K, Lindberg AM, et al. Enterovirus infection in human pancreatic islet cells, islet tropism in vivo and receptor involvement in cultured islet beta cells. Diabetologia 2004; 47: 225-39.

[22] Foulis AK, McGill M, Farquharson MA, Hilton DA. A search for evidence of viral infection in pancreases of newly diagnosed patients with IDDM. Diabetologia 1997; 40: 53-61.

[23] Foulis AK, Farquharson MA, Cameron SO, McGill M, Schonke H, Kandolf R. A search for the presence of the enteroviral capsid protein VP1 in pancreases of patients with type 1 (insulindependent) diabetes and pancreases and hearts of infants who died of coxsackieviral myocarditis. Diabetologia 1990; 33: 290-8.

[24] Bergelson JM, Cunningham JA, Droguett G, et al. Isolation of a common receptor for Coxsackie B viruses and adenoviruses 2 and 5. Science 1997; 275: 1320-3.

[25] Milstone AM, Petrella J, Sanchez MD, Mahmud M, Whitbeck JC, Bergelson JM. Interaction with coxsackievirus and adenovirus receptor, but not with decay-accelerating factor (DAF), induces Aparticle formation in a DAF-binding coxsackievirus B3 isolate. $\mathbf{J}$ Virol 2005; 79: 655-60.

[26] Shafren DR, Bates RC, Agrez MV, Herd RL, Burns GF, Barry RD. Coxsackieviruses B1, B3, and B5 use decay accelerating factor as a receptor for cell attachment. J Virol 1995; 69: 3873-7.

[27] Frisk G, Elfstrom T, Diderholm H. The replication of certain Coxsackie B virus strains in CHO cells. J Virol Methods 2001; 98: 161-5.

[28] Schmidtke M, Selinka HC, Heim A, et al. Attachment of coxsackievirus B3 variants to various cell lines: mapping of phenotypic differences to capsid protein VP1. Virology 2000; 275 : 77-88.

[29] Mena I, Fischer C, Gebhard JR, Perry CM, Harkins S, Whitton JL. Coxsackievirus infection of the pancreas: evaluation of receptor expression, pathogenesis, and immunopathology. Virology 2000; 271: 276-88.

[30] Raschperger E, Thyberg J, Pettersson S, Philipson L, Fuxe J, Pettersson RF. The coxsackie- and adenovirus receptor (CAR) is an in vivo marker for epithelial tight junctions, with a potential role in regulating permeability and tissue homeostasis. Exp Cell Res 2006; 312: 1566-80.

[31] Belov GA, Nair V, Hansen BT, Hoyt FH, Fischer ER, Ehrenfeld E. Complex dynamic development of poliovirus membranous replication complexes. J Virol 2012; 86: 302-12.

[32] Suhy DA, Giddings TH Jr, Kirkegaard K. Remodeling the endoplasmic reticulum by poliovirus infection and by individual viral proteins: an autophagy-like origin for virus-induced vesicles. J Virol 2000; 74: 8953-65.

[33] Bienz K, Egger D, Pfister T, Troxler M. Structural and functional characterization of the poliovirus replication complex. J Virol 1992; 66: 2740-7.
[34] Egger D, Bienz K. Intracellular location and translocation of silent and active poliovirus replication complexes. J Gen Virol 2005; 86: 707-18.

[35] Wessels E, Duijsings D, Niu TK, et al. A viral protein that blocks Arf1-mediated COP-I assembly by inhibiting the guanine nucleotide exchange factor GBF1. Dev Cell 2006; 11: 191-201.

[36] Schlegel A, Giddings TH Jr, Ladinsky MS, Kirkegaard K. Cellular origin and ultrastructure of membranes induced during poliovirus infection. J Virol 1996; 70: 6576-88.

[37] Rust RC, Landmann L, Gosert R, et al. Cellular COPII proteins are involved in production of the vesicles that form the poliovirus replication complex. J Virol 2001; 75: 9808-18.

[38] Goto M, Eich TM, Felldin M, et al. Refinement of the automated method for human islet isolation and presentation of a closed system for in vitro islet culture. Transplantation 2004; 78: 1367-75.

[39] Moell A, Skog O, Ahlin E, Korsgren O, Frisk G. Antiviral effect of nicotinamide on enterovirus-infected human islets in vitro: effect on virus replication and chemokine secretion. J Med Virol 2009; 81: 1082-7.

[40] Lukinius A, Wilander E, Westermark GT, Engstrom U, Westermark P. Co-localization of islet amyloid polypeptide and insulin in the B cell secretory granules of the human pancreatic islets. Diabetologia 1989; 32: 240-4.

[41] Vuorinen T, Kallajoki M, Hyypia T, Vainionpaa R. Coxsackievirus B3-induced acute pancreatitis: analysis of histopathological and viral parameters in a mouse model. Br J Exp Pathol 1989; 70: 395403.

[42] Zanone MM, Favaro E, Ferioli E, et al. Human pancreatic islet endothelial cells express coxsackievirus and adenovirus receptor and are activated by coxsackie B virus infection. FASEB J 2007; 21: 3308-17

[43] Smura T, Ylipaasto P, Klemola P, et al. Cellular tropism of human enterovirus D species serotypes EV-94, EV-70, and EV-68 in vitro: implications for pathogenesis. J Med Virol 2010; 82: 1940-9.

[44] Ida-Hosonuma M, Iwasaki T, Yoshikawa T, et al. The alpha/beta interferon response controls tissue tropism and pathogenicity of poliovirus. J Virol 2005; 79: 4460-9.

[45] Yoshikawa T, Iwasaki T, Ida-Hosonuma M, et al. Role of the alpha/beta interferon response in the acquisition of susceptibility to poliovirus by kidney cells in culture. J Virol 2006; 80: 4313-25.

[46] Flodstrom M, Maday A, Balakrishna D, Cleary MM, Yoshimura A Sarvetnick N. Target cell defense prevents the development of diabetes after viral infection. Nat Immunol 2002; 3: 373-82.

[47] Hultcrantz M, Huhn MH, Wolf $\mathrm{M}$, et al. Interferons induce an antiviral state in human pancreatic islet cells. Virology 2007; 367: 92-101.

[48] Rorsman P, Renstrom E. Insulin granule dynamics in pancreatic beta cells. Diabetologia 2003; 46: 1029-45.

(C) Hodik et al.; Licensee Bentham Open.

This is an open access article licensed under the terms of the Creative Commons Attribution Non-Commercial License (http: //creativecommons.org/licenses/by$\mathrm{nc} / 3.0 /$ ) which permits unrestricted, non-commercial use, distribution and reproduction in any medium, provided the work is properly cited. 